\title{
CARIBOU, REINDEER AND MOOSE IN ALASKA
}

\author{
By F. Fraser Darling
}

(In 1953 Dr. Darling and Dr. A. S. Leopold conducted an investigation in Alaska on behalf of the Conservation Foundation and the New York Zoological Society. Their full report is reviewed on p. 334.)

One of the chastening conclusions to which the practising ecologist comes in considering land use is that, when a habitat is initially poor or beset by some extreme environmental handicap, such as drought or cold, it is best to leave that habitat in its natural vegetation as far as possible, aligning land use with the continuance of what is the most conserving land cover. This philosophy may be dead against the older conviction that "God speeds the plough ", but detached observation of many a Scottish hillside or African range will nevertheless show it to be true. What is still more important in this philosophy is that one comes to value the natural cover of poor and marginal habitats and not just dismiss it as unimportant or undesirable.

That is the key point in land use in Alaska, an area one-fifth that of the United States. A fifth of the area of Alaska is covered with tree growth and a fifth of this is merchantable forest. As fifths seem prominent in this picture, the estimate of H. J. Lutz, Professor of Forestry at Yale, may be mentioned, that only one-fifth of Alaska's tree-covered area has escaped fire since the United States' purchase of the territory in $186 \%$.

Fire is natural in country of this kind and should not be viewed with unqualified dread. Fire sets back vegetational succession and allows more room for the animals associated with successional stages, rather than with the final and more or less stable phase. The overall picture of a large tract of country is enriched by the limited and very occasional passage of fire. But, since the advent of the United States into Alaska there can be no doubt whatever that too much of the Territory has burned too often, and the changes brought about have been profound.

Nevertheless, there is an immense area of untouched country in Alaska, where one hopes that a policy of conservation will be followed before exploitation is carried too far.

It has been said that Alaska needs people more than anything else and that the sooner the human population reaches the halfmillion mark, the better. Dr. Leopold's opinion and my own is that recent rapid expansion has been largely a function of defence spending, and that the normal pace of Alaskan develop- 
ment must be slow. Admittedly, certain administrative and economic problems are easier of solution when there are more people, but it is putting the cart before the horse to get the people there before the resources of the country can sustain them. Industrial development in Alaska, as typified by the salmon and seafood canneries, the Ketchikan pulp mill and the proposed Skagway aluminium smelting plant, are largely peripheral, and the greater part of the interior may be expected to be left alone for a long time. The indirect influences of man, however, may well be critical for the continued existence of the wild game.

The caribou was once the most numerous and widespread hoofed animal in Alaska, occupying sporadically almost all the country north of the heavy timber. This animal is extremely gregarious and is constantly on the move, so that the spectacle of a migration of tens of thousands of these wild deer probably led to the notion of limitless numbers, though this close massing meant that large areas of the country would be quite empty of caribou. Estimates of former numbers could not be founded on very sound data and it would be as well to leave them out of our thinking; what we can say with certainty is that there are now only fractional populations of what there once were in sub-arctic Alaska. A surer guide than numbers is the shrinkage of range from earlier days. The present strength of caribou in Alaska is in the arctic third of the country, and it is our opinion that the herds have increased there.

There can be no doubt that over-hunting of the caribou herds of sub-arctic Alaska was the initial reason for the reduction in numbers, but the main cause of their disappearance from such large areas has been interference with and consequent change in the character of the range. Caribou are the hardiest of the deer tribe in their capacity to withstand cold and live on the tundra and the northern forest edge. More than any other deer they have acquired the habit of subsisting on lichens. You will often hear it said that caribou and their domesticated relation the reindeer cannot live without lichen. This is hardly the whole truth, but the fact is they can eat lichen and subsist on it through the winter, and this makes it possible for them to occupy such terrain in such numbers.

Lichen, once grown, keeps its nutritive value. It is cured, as it were, and does not deteriorate as do grasses and sedges. Caribou make lichen 80 per cent of their diet in winter when grassy forage is worthless. The balance is made up from browsing twigs of willow and dwarf birch. But as soon as summer comes, grasses and sedges constitute $\mathbf{8 0}$ per cent of the diet and lichen 
only 20 per cent. It is this plentiful and nutritious summer fare which grows the great wad of fat over the loins, on which the caribou draws consistently through the winter. The lichen provides the maintenance ration. Remove the lichen and the caribou herds do not get through the winter without heavy loss. Willow browse as winter forage will carry possibly one-fifth of the numbers which can subsist when ample lichen is present.

Lichen gets tinder-dry, so that an untouched lichen tundra, such as could be found on the Seward peninsula sixty years ago, and thin forest edge with a lichen floor, can burn just as readily as a resinous spruce forest. It takes even longer to grow again. As we saw it, fire in interior Alaska has been the critical factor regulating the numbers of caribou. But in the arctic third of the country lichen is not so dense as to burn. Regeneration of range in arctic Alaska is very slow indeed, and the greatest danger there is lest the game population should so far increase as to overgraze the range. The re-growth of the lichen would be so slow that overgrazing would have immediate effects in producing starvation and a crash of the herds. That would be a calamity.

There are so few people in arctic Alaska, white or native, that they can do very little directly to build up or reduce the herds of caribou, and they can do absolutely nothing about the range, but indirect action can be just as heavy with consequence. Civilization and its slant of thought have produced the firm notion that the wolf is a bad animal, and that the twelfth commandment might well be never to make a truce with him. But take a vast area of cold country, where man can neither farm nor be a rancher, and where he cannot subsist in any considerable numbers, it may well be then that the wolf is not only the guardian of the range, but the guardian of the wild herds as well. He helps to keep them on the move and to prevent them increasing to numbers too great for the range.

As man cannot yet manage to harvest the interior of arctic Alaska, he should leave the job to the wolf meantime. This has been a hard piece of philosophy to swallow for some people, but its wisdom is evidently realized from the fact that the U.S. Fish and Wildlife Service is not this year making forays into the main body of arctic Alaska in pursuit of wolves.

Let us leave the caribou for a while and see what has happened to their Old World domesticated counterpart, the reindeer, of which 1,200 were brought from Siberia between 1891 and 1902 . They came first to the dense lichen range of the Seward peninsula and were spread by intention along the whole west coast of Alaska. Their rate of increase was phenomenal, and 
to our way of thinking their very success was the cause of the catastrophic failure of the reindeer herds in the late 1930's and early 1940's.

At the time of the importations and for too long afterwards, stocking capacity was considered in terms of one reindeer to about forty acres of range. That acreage kept a deer well enough at first, when the lichen was thick. It has been estimated that at the peak period of 1934 there were 650,000 reindeer in Alaska. By 1940 there were 250,000 and by 195025,000 . Not only had the coastal ranges been grazed out but the herds had reached such numbers that there was not manpower enough in western Alaska to manage them properly.

In those catastrophic years when the herds almost seemed to melt away, wolves and poaching were given as reasons for the crash, together with the disinclination of the Eskimo to herd the deer adequately, though when you analyse the figures in relation to districts it is apparent that the pattern was the same where there were neither wolves nor poachers and where the behaviour of the Eskimos was exemplary. The plain truth of overgrazing was too plain to be seen and understood immediately.

The course of overgrazing and overburning which has occurred over so much of the world has produced vast areas of desert. The land-use ecologist gets that idea and holds it pretty firmly, but there in western Alaska we had to sort out our ideas afresh, a painful but stimulating process. Overgrazing of the lichens on the Seward Peninsula has not produced desert; rather has it made the tundra bloom. The lichen represents a climax vegetational condition under which the shrubs and sedges of the tundra are suppressed. But remove this blanket by fire or overgrazing and the dwarf birch, willow, blueberry, cloudberry, Alaskan tea, sedges and sub-arctic grasses grow luxuriantly. It looks wonderful in summer but is not suitable for a heavy stock of reindeer because it has such little nutritive value in winter, and cannot be reached under the snow by rustling as easily as can the lichen. Western Alaska is now a vast summer range that could graze many hundreds of thousands of reindeer, but summer forage is not the bottleneck in carrying capacity for reindeer. Winter rules, and nowhere firmer than in Alaska. The present reindeer stock of about $\mathbf{2 8 , 0 0 0}$ in Alaska is very small and may cause hope for the future to fail. Rather should it be looked upon as a blessing, giving opportunity for laying firm foundations of a new native reindeer pastoralism. Figures will never again reach hundreds of thousands, but the reindeer can still make its good contribution to the meat supply of Alaska. 
To me at least it seemed that one of the biggest native social problems in Alaska is to devise means by which reindeer pastoralism can satisfy the Eskimo's intense capacity for sociability and close family life. The Lapps fitted their whole culture to the needs of their reindeer, but I do not think that as yet the Eskimo has developed the emotional tie with the reindeer which is evident in the Lapp, and which is necessary if the life of a people is to be lived round the deer.

Alaska is a new country literally, newly emerged from the ice as it were, and the events described have not had quite the devastating effects which might have been apparent nearer the tropics. Burning, and overgrazing by reindeer have, as we have seen, pushed back ecological succession from climax to secondary stages. The animals of the climax, typified by the caribou, are much reduced, but there are animals of secondary succession as well. The Alaskan moose, which is the biggest deer in the world, is such an animal. Climax forests and lichen-covered tundra are not his choice, but the course of those great braided rivers of Alaska, where the channels are constantly wearing away banks and laying down land afresh on the other side, and places where fire has passed, are the haunts of the moose. In these areas there is fairly rapid regeneration of willow growth, the moose's favourite food, and of aspen and birch, which are second choice.

The moose is not highly gregarious or given to spectacular mass movement like the caribou, and its habits of keeping mainly in cover make estimation of numbers a difficult task. The U.S. Fish and Wildlife Service has done remarkable work by aerial census, and it is evident that the Alaskan moose is far more numerous and widely spread than it was sixty years ago. One moose is equal to four or five caribou in weight, and we are seeing a gradual change-over from caribou to moose in so far as the character of the vegetation has changed. This is not to say that the total weight of all live moose has yet made up for the reduction in the total weight of all live caribou from sixty years ago.

There is one other phenomenon leading to the spread of moose to the Arctic Ocean and even as far west as Cape Prince of Wales, a factor over which man has no control. The whole arctic and sub-arctic region of the world is in a cyclic phase of warming. 'This may not seem very considerable when you see the thermometer at $55^{\circ} \mathrm{F}$. below zero, but if you visit the foot of glaciers in Alaska or Greenland, the recession of the ice is quite obvious. The careful weather records of half a century show the pace of this slight warming. Living things react to such sligh 
changes very quickly, and this fact has been the subject of some most interesting work in Finland, where it has been established that creatures of the temperate zone are pushing farther towards the arctic, and arctic species are failing to range so far south as they did half a century ago.

This effect may be studied also in Alaska. Tuna fishing is now becoming profitable in southern Alaskan waters, where there were no tuna twenty years ago, and as the willow grows stronger on the mainland the moose is ranging farther north as a continuous resident rather than as an adventurous individual. There are signs in heavy willow areas, such as the Kenai peninsula and the Susitna river country north of Anchorage, that moose are so numerous that overbrowsing is taking place; but public opinion is not ready to accept a policy of orderly reduction. The early notion of protection is firmly held, as distinct from the larger idea of conservation by ecological management.

The biological status of game animals changes from time to time, faster than does public opinion. The Fish and Wildlife Service, as an educative and administrative body as well as being an active research organization, has a difficult task to perform. Its research side does a very fine job in collaboration with the wildlife research unit of the University of Alaska. Big game research is necessarily slow and long-term, and we were particularly impressed with the enthusiasm and selflessness of the post-graduate workers in the University. These men, in their usually hard-earned year or two of research, can do little more than provide one piece in the jig-saw puzzle of an animal's life history and ecological relationships. They are members of a happy team.

Right conservation rests on applying research findings and adjusting administration with masterly flexibility. Alaska, as one of the world's finest big-game areas, needs a heavy research programme, some of it fundamental and apparently far away from actual management of game populations. It was our feeling that such fundamental research was not getting quite a good enough chance. Because there are large areas of untouched, pristine country, Alaska's value in world-wide ecological research is high. The solution of problems in Alaska can illuminate our minds when dealing with other parts, where the so-called natural scene has too often been bedevilled by human influence. A great arctic reserve in Alaska for biological research would pay in many ways, but that's another story, as Rudyard Kipling said. 